\title{
Failure temperature of a system comprising a restrained column submitted to fire
}

Jean-Marc Franssen

Institute de Genie Civil, University of Liege, Quai Banning, 6, B-4000 Liege, Belgium

\begin{abstract}
The problem of columns submitted to fire is discussed in the introduction with an emphasis on the differences between the case of a column acting as a single element or being part of a frame. In the latter case, failure of the column does not necessarily lead to the failure of the structure. The basic principles of the arc-length technique are given, first for the way it is applied traditionally at room temperature, then for the way it can be applied to extend a numerical simulation beyond the moment of local failures in case of fire. The technique is then applied to the case of restrained columns and it is shown how it is possible to obtain a safe estimate of the critical temperature of the column leading to the failure of the structure, even if the degree of restraint applied to the column is unknown.
\end{abstract}

Keywords: Column; Fire; Restraint; Numerical modelling

\section{Nomenclature}

A cross-sectional area $\left(\mathrm{m}^{2}\right)$

$B \quad$ width of a steel I profile $(\mathrm{m})$

$\mathrm{d} P, \mathrm{~d} f \quad$ variations of $\mathrm{P}$, of $\mathrm{f}$

$\mathrm{D}_{\text {ext }} \quad$ external diameter of a circular steel tube (m)

$E \quad$ Young's modulus $\left(\mathrm{N} / \mathrm{m}^{2}\right)$

$f \quad$ displacement (m)

$f_{y} \quad$ yield strength of steel at room temperature $\left(\mathrm{N} / \mathrm{m}^{2}\right)$

$H \quad$ depth of a steel I profile (m)

$K \quad$ stiffness matrix of a structure

$K_{c} \quad$ stiffness of the column $(\mathrm{N} / \mathrm{m})$

$\mathrm{K}_{\mathrm{co}} \quad$ stiffness of the column at room temperature $(\mathrm{N} / \mathrm{m})$

$K_{s} \quad$ stiffness of the spring that the structure opposes to the elongation of the column (N/m)

$\mathrm{L}_{\mathrm{c}} \quad$ length of the column (m)

$N \quad$ axial force in the column $(\mathrm{N})$

$\mathrm{P} \quad$ force $(\mathrm{N})$

$R \quad$ ratio between the stiffness of the column during the fire and the stiffness of the column at room temperature

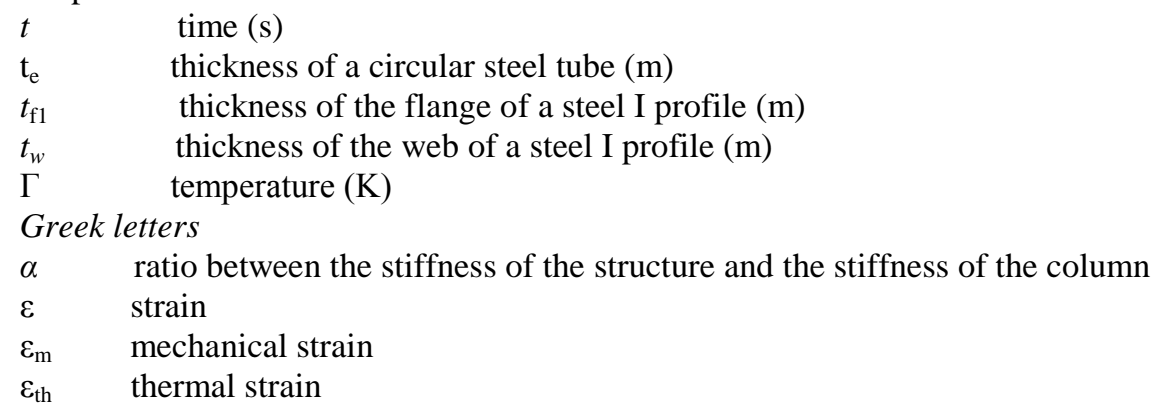

\section{Introduction}

In Europe, the most classical way of evaluating by test the fire resistance of structures is to apply a constant load on a single unrestrained element, a column or a beam for example [1]. In the US, a certain degree of restraint may be applied to beams, floors or roofs but columns are usually tested with no axial restraint [2].

In the step-by-step numerical modelling of such tests, most of the computer codes reproduce the same sequence of events. The load is first applied on the element at room temperature, in several steps if necessary, and the 
program determines the position of equilibrium of the element before the burners are turned on. The temperature is then progressively increased and the program determines the successive positions of equilibrium under the load, the value of which remains constant. After a certain amount of time, the material properties of the element have deteriorated so much that equilibrium is no more possible. In the numerical modelling, the mathematical criterion for this loss of equilibrium is the fact that the stiffness matrix of the system is no more positive definite. Physically, this means that additional displacements at this temperature would be accompanied by a decrease of the load supported by the element. It is not possible to calculate beyond this limit time, even if the time step is infinitely refined. The more the time step is refined, the closer this limit time is approached, but it is impossible to exceed this limit.

Fig. 1. Different situations with no restraint.

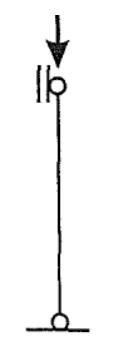

a) single column

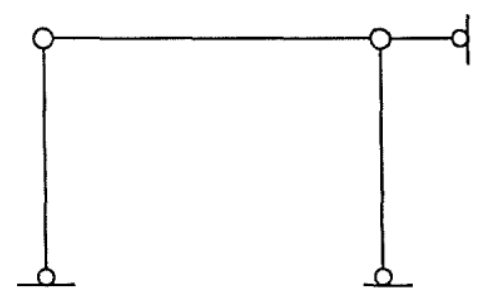

b) isostatic system

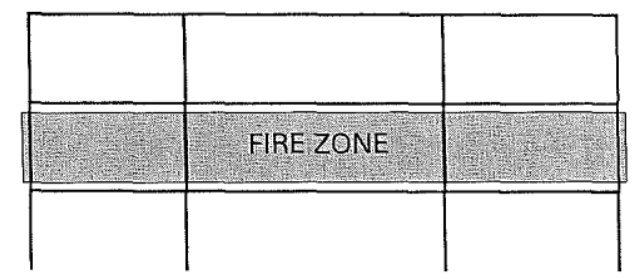

c) columns in the same situation

Fig. 2. Restraint in one column.

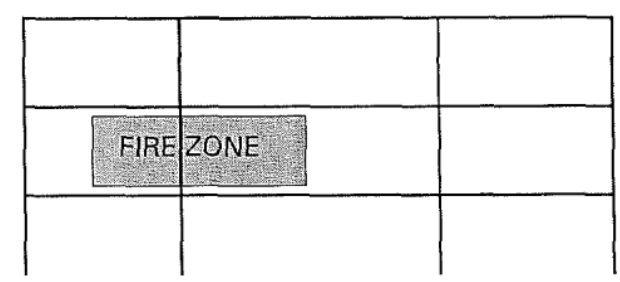

In the case of a single column as depicted in Fig. la, this limit time corresponds to the real failure defined as the loss of lo! ad-bearing capacity of the structure. The moment the column has deflected laterally — in the most common case of buckling - it is no longer capable of fulfilling the role for which it has been designed and this default of load-bearing capacity increases with increasing displacements. The same holds if the element is part of an isostatic system like the one described in Fig. lb. The situation is also similar in the common situation depicted in Fig. lc provided that the heating rate is similar in all the columns and each of them is submitted to the same load ratio. Equal heating rates ensure equal thermal elongations, which prevents induced thermal forces, and equal load ratios ensure that the time of failure is the same in all the columns. The structure cannot therefore survive the failure of one column, because all of them fail at the same time.

The situation may be totally different if a column is part of a moment resisting frame and is the only one to suffer from the effects of the fire, either because some compartmentation has been provided or due to the localised nature of the fire, see Fig. 2. Due to the restraint to thermal elongation provided by the rest of the 
structure, the axial load in the heated column will increase during the fire. The increase will be fast and important if the stiffness of the structural elements linking this column to the other columns of the same level is important. The restrained column will therefore fail earlier than if it was submitted to a constant load.

This problem has attracted the attention of different researchers, especially since the concept of localised fire is more and more accepted and taken into account. For the analyses, the structure is generally represented by the simple system shown in Fig. 3. In this system, the spring is given the appropriate stiffness so as to represent the effect of the rest of the structure on the column. Most often, the spring has a linear behaviour, which in fact introduces the hypothesis that the rest of the structure can accommodate the vertical displacements of the column and remain in an elastic state.

In 1994, Wang and Moore analysed the problem numerically and proposed a simple equation to evaluate the increase of axial force induced by the axial restraint $[3,4]$. This equation, similar to the one proposed earlier by Petterson, is as follows:

$$
\Delta N=\frac{\alpha}{1+\alpha} K_{\mathrm{c}}\left(\varepsilon_{\mathrm{th}}-\Delta \varepsilon_{\mathrm{m}}\right) L_{\mathrm{c}}
$$

where

$$
\alpha=\frac{K_{\mathrm{s}}}{K_{\mathrm{c}}}
$$

Fig. 3. Simple model of a restrained column.

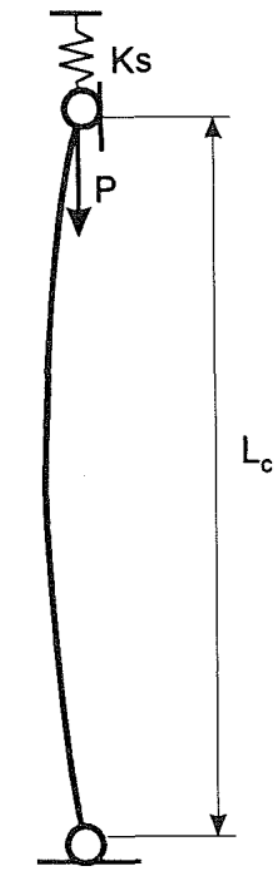

$\Delta N$ is the increase of axial force in the column, $K_{\mathrm{c}}$ is the stiffness of the column, varying as a function of time, $K_{s}$ is the stiffness of the spring, i.e. of the rest of the structure, $\varepsilon_{\text {th }}$ is the thermal strain at this temperature, $\Delta \varepsilon_{m}$ is the variation of the mechanical strain at constant stress due to the variation in the constitutive law, and $L_{\mathrm{c}}$ is the length of the column.

The non dimensional coefficient $\alpha$ used in Eq. (1) is not very convenient to characterise the situation because it is time dependent. The following equation is more appropriate than Eq. (1) because it is based on a fixed coefficient representing the ratio between the stiffness of the structure and the stiffness of the column evaluated at room temperature. 


$$
\Delta N=\frac{R}{K_{\mathrm{c}} / K_{\mathrm{co}}+R} K_{\mathrm{c}}\left(\varepsilon_{\mathrm{th}}-\Delta \varepsilon_{\mathrm{m}}\right) L_{\mathrm{c}},
$$

where

$$
R=\frac{K_{\mathrm{s}}}{K_{\mathrm{co}}}
$$

and $K_{c o}$ is the stiffness of the column at room temperature.

The authors show by a parametric study that Eq. (1) is in good agreement with their numerical results. Failure does not necessarily occur when the axial force in the column reaches its maximum value but, most often, when the force has started to decrease due to the fact that the loss of stiffness of the column becomes predominant compared to the thermal elongation. Except in very short columns heavily loaded, the failure temperature is lower than that in an unrestrained column. The reduction may be substantial, especially when the restraint is significant. Even the case of perfect restraint is examined by the authors. As a conclusion, it is said that axial restraint can be a very severe phenomenon for columns submitted to fire.

Bennets et al. have also worked on the same problem and have evaluated the degree of restraint provided to the columns by 3 different buildings of respectively 5,10 and 20 floors [5]. Their study is rather detailed because they take into account

- cracking in concrete, which leads to a stiffness of the composite steel concrete beams depending on the type of bending, either sagging or hogging,

- the stiffness of the connections, initially designed as hinged but treated here as semi-rigid,

- the axial stiffness of non-heated columns, etc.

The authors conclude that axial restraint has no such negative influence as is generally considered. To quire at this result, they have used the hypotheses that the thermal elongation has an effect only on $3 / 4$ of the length of the column and that the column will have a plastic shortening of $2 \mathrm{~mm}$ before failure.

Two different aspects of the question of restraint to columns in fire are examined in the present paper.

The first aspect is related to the difficulty in evaluating quantitatively the degree of axial restraint provided by a structure to a column. Bennets et al. determine this coefficient " $R$ " analytically, which implies the iterative resolution of a system of equations having as many unknowns as floors in the building. Of course, the solution could also be found by a conventional numerical program for the analysis of structures according to the procedure illustrated in Fig. 4. The problem nevertheless remains that, as mentioned by Bennets et al., they had to introduce some "safe" hypotheses in the modelling of the building and this will be the case irrespective of the tool used to calculate the stiffness. Several secondary contributions will always have to be neglected whereas it is difficult to estimate their real influence on the stiffness of the structure. This is, for example, the case with the shear resistance of walls not initially designed as shear walls, or with some 3D effects normally not taken into account in a normal design when parallel and similar frames are submitted to the same loading. If the axial restraint is so important, how do we cope with the fact that its true value can hardly be calculated?

The second aspect, covered neither in the two research works mentioned previously nor in the recent experimental work by Ali et al. [6], is linked to the fact that the failure of an individual column does not necessarily lead to the failure of the structure. It is in fact possible that, after this failure of the column has occured, the part of the load which cannot be supported by the buckling column is redistributed to other elements and the structure moves to another position of equilibrium. In fact, the rest of the structure which acted to increase the load before failure of the column will later act similarly to provide another load path for this part of the load that the column cannot sustain anymore. At this precise moment corresponding to the failure of the column, the stiffness matrix of the structure is also not positive definite and it is impossible for the numerical program to calculate beyond this limit time, except if particular procedures have been implemented and are activated.

In this paper, the basic principle of the arc-length technique at room temperature is first summarised. Then, it is shown with an academic example how this technique can be used to pursue the calculation beyond the limit time corresponding to local failure of a restrained and heated column. The problem of restrained columns is finally analysed and a solution is proposed to evaluate the temperature leading to the failure of the structure without the need to evaluate the degree of restraint. More information can be found in the Ref. [7]. 
Fig. 4. Calculation of the stiffness of the structure.

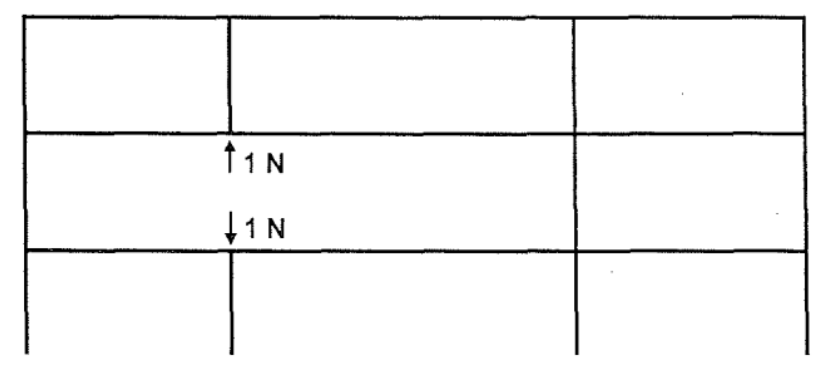

\section{The arc-length technique at room temperature}

This technique, linked to the name of Crisfield [8], is now a standard one among the tools of computational mechanics.

Only the basic principle will be exposed here and, for reasons of clarity, this technique will be explained on a simple structure (see Fig. 5) the evolution of which can be described by the evolution of one force, $P$, and one displacement, $f$, so that it is possible to represent the trace of the evolution in a $f-P$ two dimensional plan, see Fig. 6.

The equation of equilibrium of the structure can be written in the following general incremental form:

$$
\mathrm{d} P=K(f) \mathrm{d} f
$$

where $K$ is the stiffness matrix, here a scalar, of the structure.

In order to solve Eq. (3), an additional condition has to be added.

In the most commonly used procedure, this constraint equation concerns the applied force. In each step the variation of the applied force is chosen by the user, see Eq. (4):

$$
\mathrm{d} P=\text { prescribed value }
$$

This procedure allows to calculate the positions of the structure from the origin 0 until the point A corresponding to an horizontal tangent on the curve of Fig. 6, but it is not generally possible to go beyond this point, regardless of the refinement of the load step.

One possibility of calculating the behaviour of the structure beyond the peak load of point A and of tracing the snap-through behaviour is to prescribe the variation of the displacement according to.

$$
\mathrm{d} f=\text { prescribed value }
$$

Another possible constraint equation links the incremental force and the incremental displacement. It has the following general form:

$$
\mathrm{d} P^{2}+\mathrm{d} f^{2}=r^{2}
$$

where $r$ is a scalar prescribed value. 
Fig. 5. Simple structure.

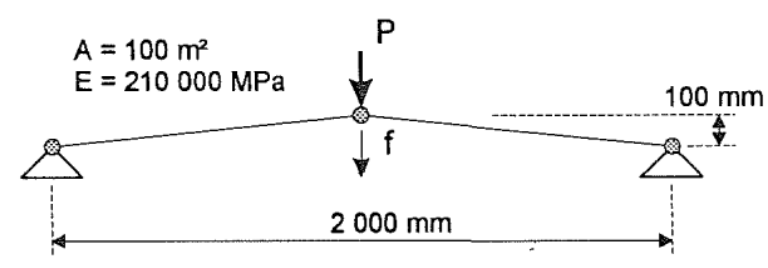

Fig. 6. Load-displacement curve.

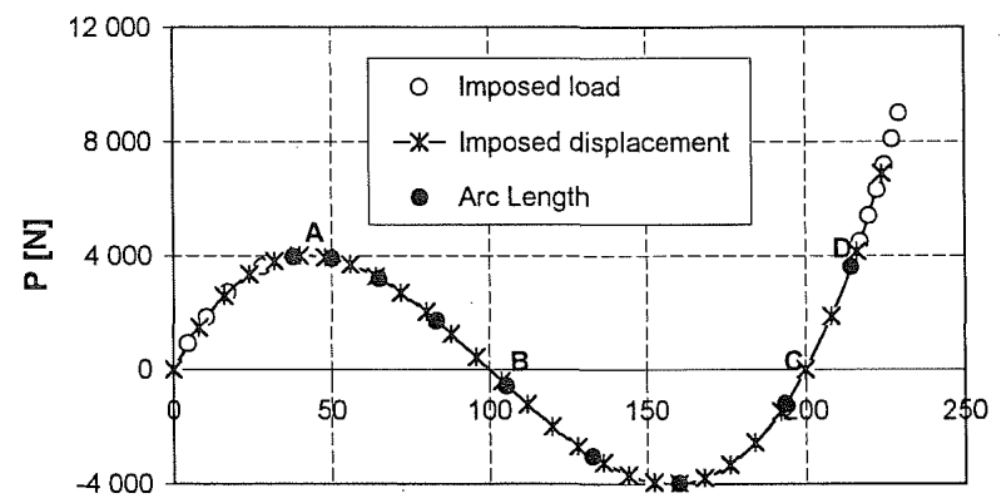

This equation describes a circle in the $f$ - $P$ plane with its centre located on the last converged point and a radius $r$, hence the name arc length method. This procedure is more general than the procedure of imposed displacement, particularly in structures with several degrees of freedom or in structures exhibiting a snap-back behaviour. The structure described in Fig. 7 has several degrees of freedom and exhibits a snap-back behaviour. The corresponding curve in the $f$ - $P$ plane has been drawn in Fig. 8 from the results obtained with the code SAFIR established at the University of Liege for the simulation of the behaviour of structures submitted to the fire. It can be noticed that the radius of the arc length $r$ is automatically adapted by the code from one step to the other in order to accelerate or slow down the procedure, depending on the number of required iterations needed to obtain equilibrium at the last converged point. A snap-back behaviour is observed on the curve beyond point A, when the displacement and the force simultaneously exhibit a negative variation. This example is academic but has been chosen to illustrate how robust the procedure can be.

Fig. 7. Structure with a complex behaviour.

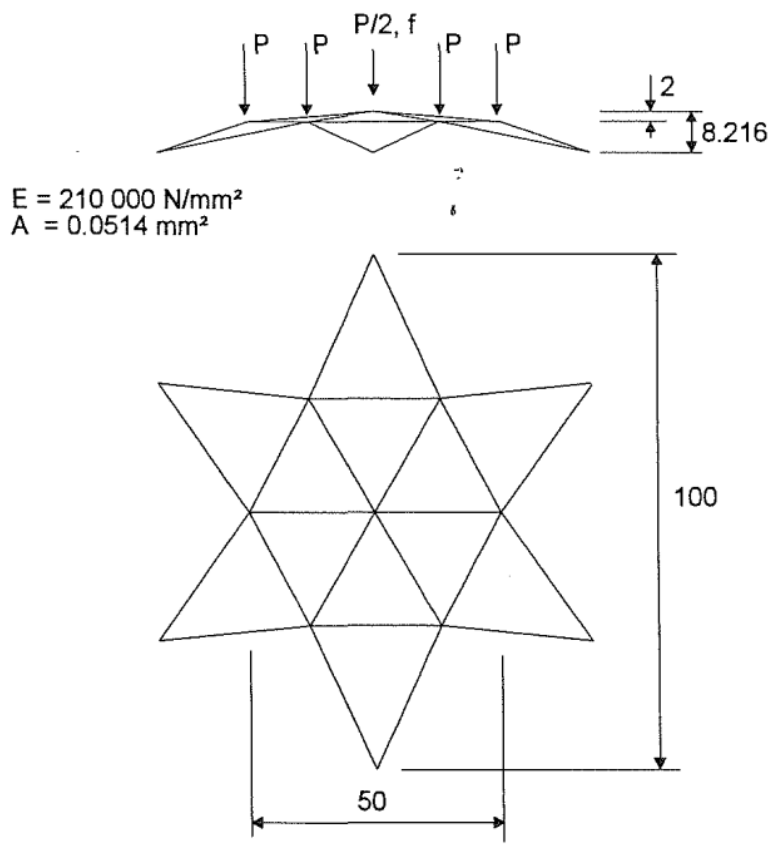


Fig. 8. Load-displacement curve.

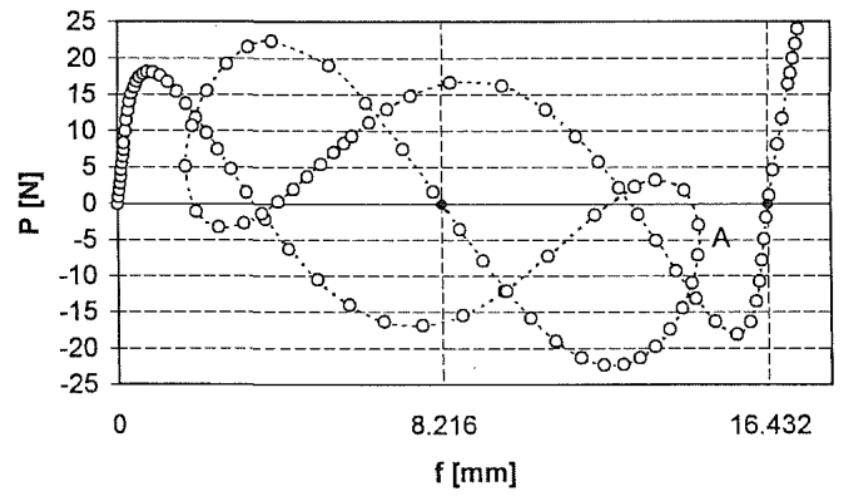

Fig. 9. Computation strategy in case of fire.

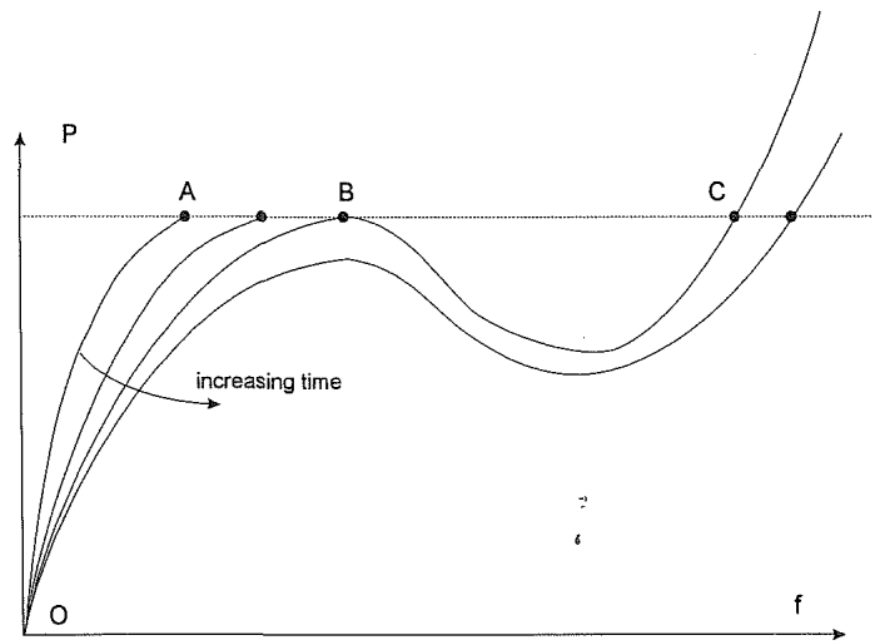

\section{The arc length technique in case of fire}

In case of fire, the load displacement curve evolution can be explained in Fig. 9, which shows different loaddisplacement curves corresponding to different moments in time, i.e. to different temperatures in the structure. The curve on the left is for ambient temperatures. The load is first applied at room temperature - applied load procedure - and the equilibrium point moves on the curve from the origin 0 to the point $\mathrm{A}$. The structure is then progressively heated under a constant load and the program calculates the new positions of the structure, taking into account the variations of material properties and the effects of large displacements. The point moves progressively from point $\mathrm{A}$ to the right. With the traditional applied load procedure, it is not possible to calculate beyond time $t_{B}$ corresponding to the moment when the load-displacement curve is such that the point representing the situation has reached a position on the curve where this curve is horizontal, point B in Fig. 9.

If the arc length procedure has been implemented, it is possible to obtain from the programme that, when the time step has been reduced to a prescribed limit value, say $1 \mathrm{~s}$, and it is no longer possible to find a solution, then the time (and, consequently, the temperature field) is temporarily fixed and the arc length procedure is activated to move beyond point $\mathrm{B}$ on the same load-displacement curve corresponding to $t_{\mathrm{B}}$. If the program can find on the curve another position of equilibrium where the structure can again support the applied load, point $\mathrm{C}$ in Fig. 9 , then it is concluded that the negative stiffness observed on point $\mathrm{B}$ corresponds to a local failure which has been accommodated by the structure. The temperatures are increased again from this point and the evolution of the structure is calculated under the applied load until another horizontal tangent is found, which generally corresponds to the real failure of the structure except in very highly redundant structures.

This procedure is exemplified with the structure described in Fig. 10. 
The horizontal cantilever I beam is not sufficient to support the applied load $P$ of $100 \mathrm{kN}$ and hence it is supported by the inclined steel tube acting as a stanchion. The hypothesis is that only the steel tube is submitted to the effect of the fire. Fig. 11 describes the evolution of the force supported by the beam and by the stanchion, whereas Fig. 12 describes the evolution of the vertical displacement at the point of application of the load. In both diagrams, the temperature in the steel tube is on the horizontal axis.

When the load has been applied at room temperature, in one single load step, it can be noticed that the stanchion supports $93.4 \mathrm{kN}$ whereas the beam supports only $6.6 \mathrm{kN}$, see points A in Fig. 11. The displacement is $1.7 \mathrm{~mm}$ downward, see point A in Fig. 12.

The temperature is then progressively increased in the steel tube. Due to the thermal elongation of the material in the stanchion, the point of application of the load moves upward by several millimetres, see Fig. 12. For a temperature of $267^{\circ} \mathrm{C}$, this point is $12.8 \mathrm{~mm}$ higher than in the initial configuration, point B in Fig. 12. The stiffness of the beam which opposes to the movement increases the vertical reaction supported by the stanchion up to a maximum value of $154 \mathrm{kN}$, points B in Fig. 11. The beam itself is forced upward by a vertical force of 54 $\mathrm{kN}$, so that the complete structure still supports the applied force of $100 \mathrm{kN}$.

Fig. 10. Structure with local failure.

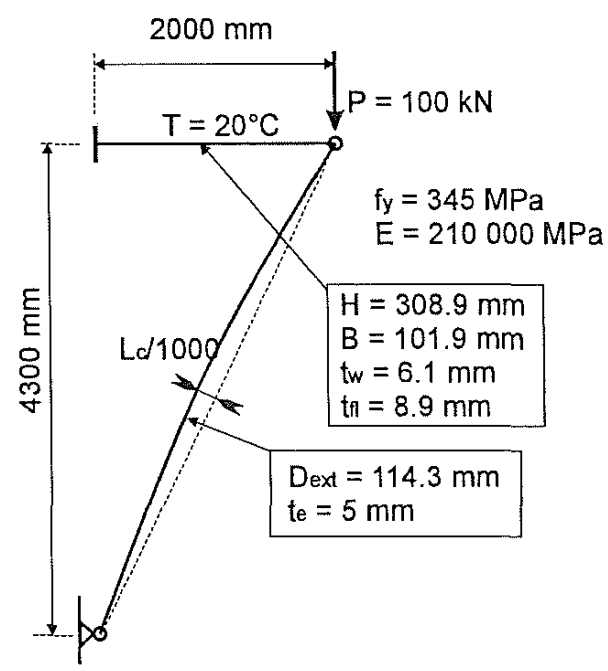

Fig. 11. Evolution of the reaction forces.

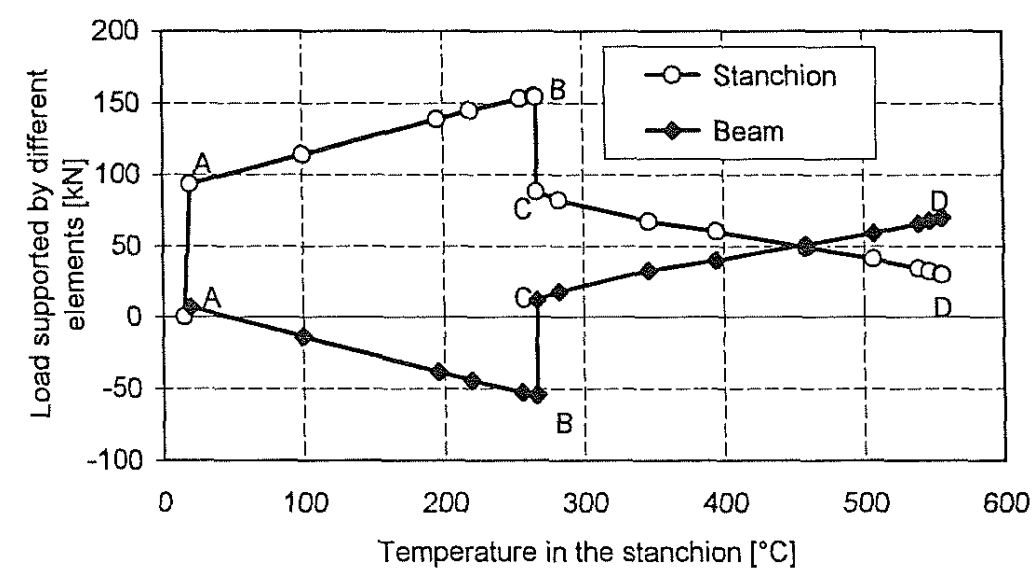


Fig. 12. Evolution of the displacement.

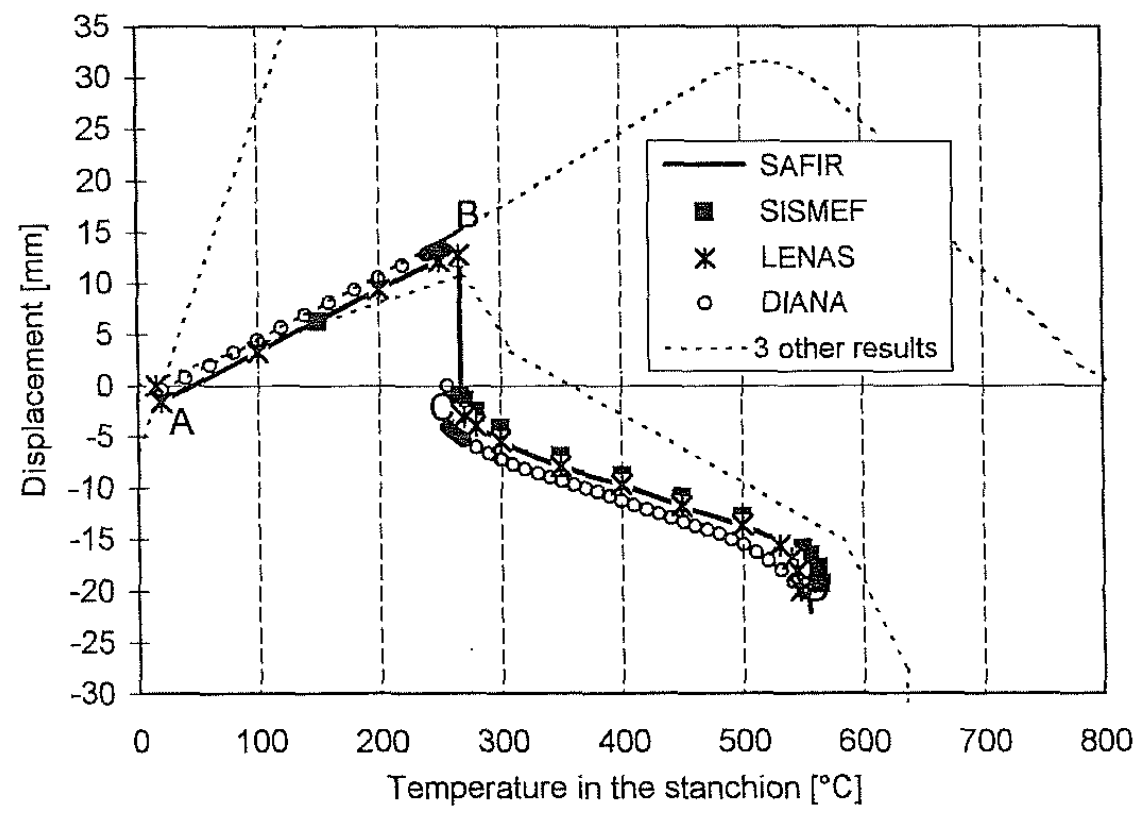

With conventional algorithms, it is not possible to exceed the limit temperature of $267^{\circ} \mathrm{C}$, no matter how small the time step may become.

In the SAFIR simulation of this case, the temperature has been fixed from this point and the arc length technique applied so that the applied load is allowed to decrease then to increase again during a moment which has no duration, until another position of equilibrium has been found, points $\mathrm{C}$ in Figs. 11 and 12. The transition from $\mathrm{B}$ to $\mathrm{C}$ corresponds to the buckling of the stanchion which bows laterally and sees its two ends coming closer to each other because the point of application of the load is now $2.8 \mathrm{~mm}$ downward. The load supported by the stanchion in this position is yet not equal to zero. It still corresponds to a vertical reaction of $88.2 \mathrm{kN}$. From B to $\mathrm{C}$ a load of $66.1 \mathrm{kN}$ has been transferred from the stanchion to the beam which, in this new position, supports $11.8 \mathrm{kN}$ of the applied load.

Having found this new position of equilibrium, it is possible to increase again the temperature in the steel tube. The effects of the geometrically unstable position in which the stanchion is, and the fact that the heating decreases the stiffness and the strength of steel, take the lead on the thermal elongation. The displacement of the point is downward. The final failure of the structure is obtained for a steel temperature of $556^{\circ} \mathrm{C}$, when the load supported by the stanchion has decreased to $29.7 \mathrm{kN}$ and the beam cannot support more than the $70.3 \mathrm{kN}$ it supports at this moment in time, points D in Fig. 11. The deflection just before failure is $22.1 \mathrm{~mm}$, point $\mathrm{D}$ in Fig. 12.

In Fig. 12 are shown the curves obtained by the codes LENAS and SISMEF from CTICM. with a secant matrix procedure, and by the code DIANA from TNO using the arc length technique [9]. Three other curves obtained by other codes are shown, proving that very different results can be obtained if the phenomenon of local failure is not appropriately treated.

The arc length technique is not the only procedure leading to a good solution of the problem. The secant matrix procedure has been mentioned, although it should be verified whether it has the same robustness as the one usually recognised to the arc length technique. The problem can of course be treated by a full dynamic analysis but this requires to establish another set of differential equations, with additional matrix and other time integration algorithms. The required CPU time varies also according to the complexity of the equations. A technique such as the arc length technique is easily implemented in a code which was originally based on applied forces or applied displacements, is robust and provides an appropriate solution to the problem of local failure in structures submitted to the fire. 
Regardless of the procedure used to exceed the limit point $\mathrm{B}$, it has to be recognised that the utilisation of a code which would be unable to keep on working beyond the moment of local failure could lead to a very severe underestimation of the failure temperature or fire resistance of redundant structures.

\section{Restrained columns submitted to fire}

A system similar to the one described in Fig. 3 is analysed with the following values:

- length of the column $4 \mathrm{~m}$,

- section HE A 100,

- buckling major axis,

- yield strength $235 \mathrm{MPa}$,

- Young modulus $210000 \mathrm{MPa}$ • material model Eurocode 3,

- initial axial force in the column $50 \mathrm{kN}$,

- stiffness of the structure varying from case to case.

The degree of restraint provided by the rest of the structure is varied and makes the difference between the different simulations. The relative stiffness $R$ varies from 0 , i.e. no restraint, to co, i.e. a full restraint. The order of magnitude of restraint in real buildings is usually of the order of magnitude of $2-3 \%$ [3].

The external load applied on the system changes from one simulation to another as a function of the restraint in order to induce in the column an initial axial load of $50 \mathrm{kN}$ in all cases. With a restraint $R$ of 0.10 , for example, $P$ is given the value of $55 \mathrm{kN}$. We want to place ourselves in the situation where the analysis of the global structure at room temperature has given an axial force in the column of $50 \mathrm{kN}$, whatever the restraint be. Only the evolution of the axial force during the fire will be influenced by the restraint.

Fig. 13 shows for six different degrees of restraint the evolution of the axial force in the column as a function of the temperature in the column, which is supposed to be uniform.

A first simulation is made with no axial restraint at all, i.e. $R=0$. The axial force remains constant and the failure is obtained for a temperature of $652^{\circ} \mathrm{C}$, see Fig. 13 .

Fig. 13. Evolution of the axial force.

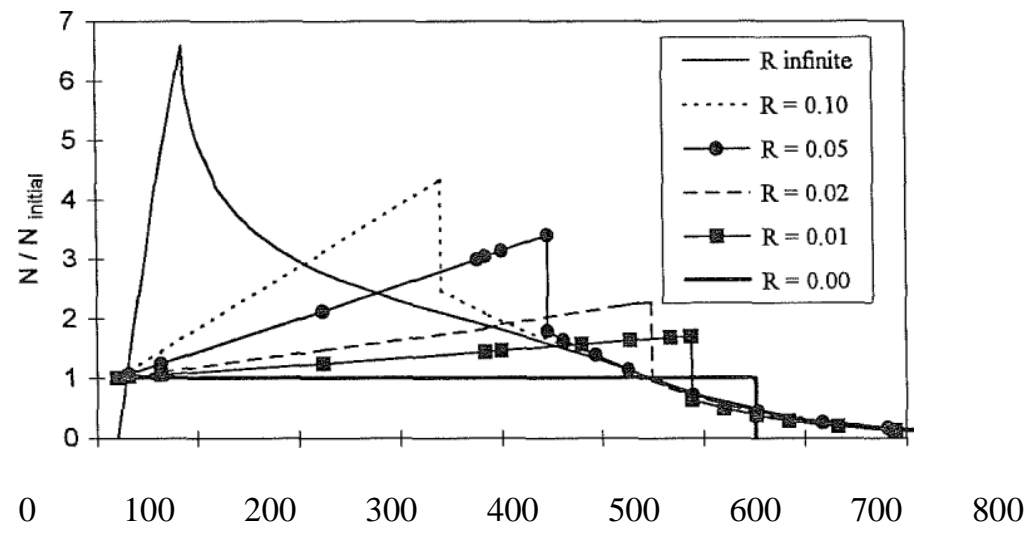

Temperature in the column $\left[{ }^{\circ} \mathrm{C}\right]$

For a degree of restraint of $1 \%$, the axial force in the column increases progressively during the heating, up to a temperature of $590^{\circ} \mathrm{C}$ when the increase has reached $75 \%$. At this temperature, buckling of the column occurs and a part of the load supported by the column is transferred to the spring. In the next position of equilibrium, the column is still able to support $75 \%$ of the $50 \mathrm{kN}$ it supported initially. The temperature can then be increased indefinitely, up to the moment when the steel in the column has completely melted and the load is totally supported by the spring. Of course, this happens for a very large vertical displacement, calculated here to be 45 $\mathrm{mm}$. The behaviour is in fact only realistic provided that the rest of the structure - represented by the spring - 
is resistant enough to accommodate this deflection and still remains elastic. What is sure is that if the column submitted to the fire has been designed to support the load of $50 \mathrm{kN}$, the rest of the structure is not in danger as long as the column supports at least $50 \mathrm{kN}$, i.e. to a failure temperature of $590^{\circ} \mathrm{C}$. It will be shown later that this is a very safe hypothesis and that the structure can normally survive to a higher temperature.

For a degree of restraint of $2 \%$, the increase of the axial force in the column is faster and the buckling of the column occurs earlier, for a steel temperature of $550^{\circ} \mathrm{C}$ when the axial force in the column has more than doubled. After buckling, however, the heated column is still able to support exactly the same amount of force as the one for which it had been designed, i.e. $50 \mathrm{kN}$. If we still consider that this constitutes the definition of failure for the system, the failure temperature of the structure is also $550^{\circ} \mathrm{C}$.

For any degree of restraint higher than $2 \%$, the buckling of the column occurs at a temperature lower than $550^{\circ} \mathrm{C}$, say $445^{\circ} \mathrm{C}$ for a restraint of $5 \%$. In any analysis where the simulation does not allow to calculate beyond the local failure, this temperature causing the buckling of the column will be considered as the failure temperature of the structure and the axial restraint will appear as having a very severe influence. Here, it can be seen that the column is still sufficiently cold when it buckles and can therefore still support more than the load it supported before the fire. The structure is certainly not in danger at this moment in time and the temperature in the column can be increased further.

What is important to notice is that the temperature in the column for which this one has its load-bearing capacity reduced to the initially applied force of $50 \mathrm{kN}$ is also $550^{\circ} \mathrm{C}$, which was the failure temperature for the system when the restraint had a value of $2 \%$. In fact, for any degree of restraint higher than $2 \%$, the column is able to support the initial load of $50 \mathrm{kN}$ as long as the temperature in the column does not reach $550^{\circ} \mathrm{C}$.

It is therefore possible to determine a safe approximation of the temperature of the column which leads to the failure of the structure, even if the actual degree of restraint is unknown. The three-step procedure is as follows.

1. The column is first analysed as a totally restrained single element submitted to the action of the fire. This, by the way, can be done with a conventional algorithm. There is no need to implement or use the arc length technique. No external load can be applied on the column in the initial stage, because the displacement of both ends of the column is prevented. The calculation is done until very high temperatures of $800^{\circ} \mathrm{C}$ or more. The evolution of the axial force in the restraint column is shown in Fig. 14.

2. The complete structure is then analysed at ambient temperature as submitted to the loads acting during the fire. The value of the axial force $N$ in the column is noted from this analysis.

3. The temperature of the column leading to the failure of the structure is read on the curve when the load induced in the restraint column falls below the axial force initially applied in the real column, $N$. In the example of Fig. $14, N=65 \mathrm{kN}$ leads to a failure temperature of $500^{\circ} \mathrm{C}$.

The actual degree of restraint provided by the structure is unknown but we know that if it is lower than a limit value - here $2 \%$ but this value also does not need to be calculated - the failure temperature will be higher than $500^{\circ} \mathrm{C}$. If, on the other hand, the actual restraint is higher than the limit value, $500^{\circ} \mathrm{C}$ will be the temperature of the column leading to the failure of the structure, defined as the moment when the column cannot anymore support the load it supported before the fire.

In the above discussion, the failure criterion for the structure was defined as the moment when the column is no more able to support the load which it supported before the fire. This definition is very severe. It has been introduced to ensure that the other columns at the same level are not submitted to a load higher than the one they supported before the fire. In reality, the load supported by a structure before a fire is usually very far from its ultimate load-bearing capacity, and so there exists a safety margin in the unexposed columns and these ones can normally support a significant increase of loading. Any structure has indeed been designed (a) to support the design load, (b) existing at room temperature, and (c) taking into account the design values of the material properties. In the case, for example, where the partial safety factor on loads at room temperature was equal to 1.50 , where the partial safety factor on the material in a concrete column was equal to $0.85 / 1.50=1 / 1.76$, and the load in case of fire was only $60 \%$ of the load used for the room temperature design, the load-supported by the column before the fire is only $0.60 /(1.50 \times 1.76)=23 \%$ of its ultimate load-bearing capacity at room temperature. This ratio can even be lower if the provided section is for any reason stronger than the strictly required section. The ratio has to be appreciated on a case-by-case basis but in the most unfavourable situation, with a partial safety factor of 1.35 on the load and of 1.00 on the material strength and with the full design load 
acting in case of fire, the load ratio in the columns before the fire cannot be more than $1 / 1.35=74 \%$. This means that the unheated columns can support an increase of the load of at least $35 \%$ during the fire. From this value, it is not difficult to derive the load that the heated column must still be able to support during the fire in order to prevent the failure of the structure.

If, for example, the heated column is the central support of a continuous beam supported by 3 columns, then simple equilibrium equations show that the failure of the system can be prevented as long as the central column is able to support the initial load minus two times the reserve existing in the edge columns (provided that the load can be transferred from a column to the others by the bending in the beam).

If the heated column is one of the edge columns, then it must be able to sustain the initial load minus one-half of the reserve existing in the central column.

Having determined the load which the heated column must still sustain during the fire to prevent the failure of the structure, it is easy to take it into account in the curve giving the evolution of the axial force as a function of the temperature in the fully restrained column (see Fig. 14) and to read the temperature of the column leading to the failure of the structure. This value would in any case be higher than $500^{\circ} \mathrm{C}$ if it were taken from Fig. 14 .

Taking this into account, the conclusion of Bennets et al. that axial restraint in heated column is not as severe as generally considered can indeed be supported, although it has not been necessary to use in this study the same hypothesis as the one introduced by Bennets et al., see Section 1.

Fig. 14. Principle of the simple method.

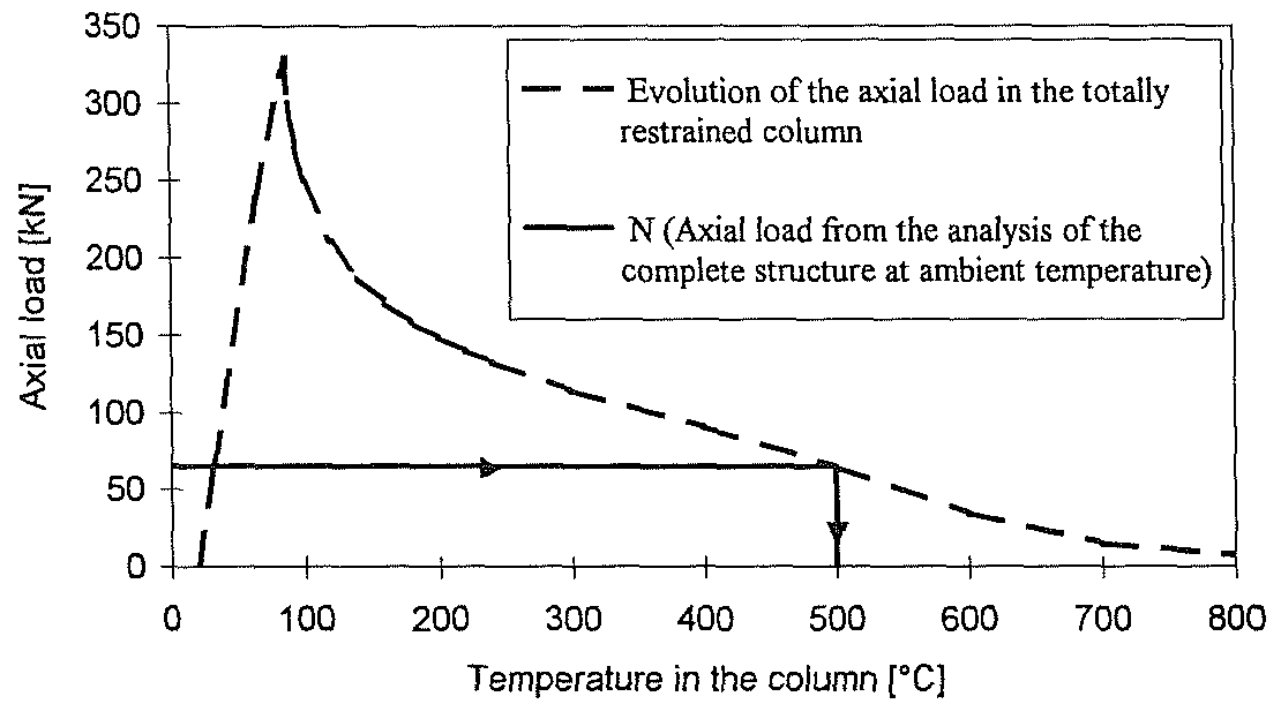

\section{Conclusions}

If a column is axially restrained during a fire, this is because a surrounding structure is present. The failure of the column may be accelerated by this restraint but it does not necessarily lead to the failure of the whole structure. The same phenomena which induce the axial restraint can work to provide another path to the load which cannot be supported by the column.

In order to model the behaviour of the structure beyond the moment of local failure, special numerical techniques have to be implemented. The arc length is one of them, particularly robust and easy to implement.

The temperature of the heated column leading to the failure of the structure can be estimated by modelling the heated column as totally restrained, which suppresses the necessity to evaluate the degree of restraint provided 
by the rest of the structure on the column.

Because the load level in the unheated columns before the fire is usually less than their ultimate load bearing capacity, the failure of the structure will occur when the heated column supports less load than the initial load it supported before the fire. This makes the axial restraint a much less severe phenomenon than it has sometimes been imagined. In some cases, it could indeed be a positive phenomenon, provided the local failure of a column is accepted and only the failure of the complete structure has to be prevented.

\section{References}

[1] NBN 713-020. Resistance au feu des elements de construction, IBN, 1968.

[2] ASTM E119-95a. Standard test methods for fire tests of building construction and materials. ASTM,1995.

[3] Wang YC, Moore DB. Effect of thermal restraint on column behaviour in a frame. In: Moore DB, editor, 4th International Symposium on Fire Safety Science, Ottawa, IAFSS, Kashiwagi T, editor,1994. p. 1055-66.

[4] Wang YC, Moore DB. The effect of frame continuity on the critical temperature of steel columns. Third Kenrensky Conference on Global Trends in Structural Engineering, Singapore, 1994. p. 681-6.

[5] Bennets ID, Poh CC, O'Meagher AJ, Thomas JR. Restraint of compression members in fire, B.H.P. Melbourne Research Lab. Report No. MRL/PSGS/89/002, 1989.

[6] Ali FA, Shepherd P, Randall M, Simms IW, O'Connor DJ, Burgess I. The effect of axial restraint on the fire resistance of steel columns. J. Constr. Steel Res. 1998, 46:1-3. Paper No. 177

[7] Franssen J-M. Contributions a la modélisation des incendies dans les bâtiments et de leurs effets sur les structures. These d'agr. de l'ens, sup., Univ. of Liege, F.S.A., 1997.

[8] Crisfield MA. An arc-length method including line searches and accelerations. Int J Numer Meth Engg, 1983;19:1269-89.

[9] Both C, van Foeken RJ, Twilt L. Analytical aspects of the cardington fire test programme, Second Cardington Conference, Cardington, UK, 1996. 